\title{
Jornalismo e pandemia - Impactos da Covid-19 nas rotinas de produção do jornalismo independente
}

\author{
Edgard Patrício ${ }^{1}$
}

\section{Resumo}

Em fevereiro de 2020, o vírus Sars-CoV-2 é detectado no Brasil. O primeiro óbito, decorrente da doença por ele causada, vem em março. Também em março é notificado o primeiro caso e a primeira morte por Covid-19 no Ceará, e o estado decreta estado de emergência. Medidas de restrição à mobilidade são determinadas. A situação mexe com o funcionamento da produção do jornalismo. Pesquisas nacionais (FÍGARO, 2020; FENAJ, 2020) atestam a repercussão da pandemia nas condições e relações de trabalho de comunicadores e jornalistas. Esse estudo busca, para além da repercussão sobre os trabalhadores, perceber as alterações causadas pela disseminação do vírus sobre as iniciativas de jornalismo independente do Ceará. Constatam-se movimentos contrários verificados pelas pesquisas referidas, o que dá conta de especificidades relacionadas às rotinas de produção do jornalismo dessas iniciativas.

Palavras-chave: Jornalismo independente. Pandemia. Covid-19.

\section{Journalism and the pandemic - Impacts of Covid-19 on the production routines of independent journalism}

\section{Abstract}

In February 2020, the Sars-CoV-2 virus is detected in Brazil. The first death, resulting from the disease caused by it, comes in March. Also in March the first case and the first death by Covid-19 in Ceará are notified, and the state decrees a state of emergency. Mobility restriction measures are determined. The situation affects the

1 Jornalista. Professor do Curso de Jornalismo e do Programa de Pós-graduação em Comunicação da Universidade Federal do Ceará. Grupo de Pesquisa PráxisJor - Práxis no Jornalismo.edgard@ufc.br 
production of journalism. National surveys (FÍGARO, 2020; FENAJ, 2020) attest to the impact of the pandemic on the conditions and working relationships of communicators and journalists. This study seeks, in addition to the repercussion on workers, to understand the changes caused by the spread of the virus on Ceará's independent journalism initiatives. Contrary movements verified by the referred researches are verified, which accounts for specificities related to the journalism production routines of these initiatives.

Keywords: Independent journalism. Pandemic. Covid-19.

\section{Introdução}

Em 26 de fevereiro é confirmado, pelo Ministério da Saúde, o primeiro caso de contaminação pelo novo coronavírus no Brasil. O primeiro óbito causado pela nova pandemia ocorre em 17 de março, na cidade de Miguel Pereira, no Rio de Janeiro. A vítima trabalhava na casa de uma mulher recém-chegada de uma viagem à Itália. Os primeiros três casos de contágio confirmados no Ceará são divulgados em 15 de março. No dia 16 de março, o governo do estado do Ceará decreta situação de emergência estadual por conta da pandemia. E em 19 de março estabelece medidas restritivas à mobilidade das pessoas. No dia 26 de março acontece a primeira morte por Covid-19 no Ceará, na capital, Fortaleza.

No contexto das medidas preventivas em relação ao controle da circulação do vírus, o jornalismo é considerado serviço essencial. Assemelha-se, assim, aos serviços de saúde, ficando de fora de decretos sanitários que estabeleceram a restrição da mobilidade. Mesmo nessa condição, a situação força a alterações nas rotinas de produção do jornalismo. Profissionais pertencentes aos grupos de riscos assumem o home office, medida seguida logo depois por um contingente maior de jornalistas, que veem suas casas serem transformadas em sucursais da redação.

Numa pesquisa realizada em 77 países $^{2}$, com a participação de 1.308 jornalistas, a Federação Internacional de Jornalistas (FIJ) atesta que mais de um terço dos respondentes indicaram que foram remanejados de suas temáticas habituais de cobertura. $\mathrm{E}$ mais da metade tem sofrido processos de estresse e ansiedade resultantes do contexto e alteração do ritmo do trabalho. Na América Latina, $63,8 \%$ dos jornalistas

\footnotetext{
2 Disponível em https://www.ifj.org/es/centro-de-medios/noticias/detalle/category/pressreleases/article/al-descubierto-la-crisis-del-periodismo-por-el-covid-19.html. Acesso em $30 / 7 / 2020$.
} 
que responderam à pesquisa admitem mudanças negativas em sua função laboral. Quanto às empresas jornalísticas, um terço estimulou o teletrabalho e, como consequência dessa modalidade, $32,4 \%$ dos jornalistas indicaram trabalhar mais que o período anterior à pandemia.

Pela pesquisa realizada pela FIJ, na América Latina o trabalho independente, por conta própria, também sofreu consequências. A porcentagem de autônomos o freelancers em atividade antes do período da pandemia superava os 35\%. No final de abril, quando foi feito o levantamento, ocorreu uma diminuição para em torno de $12 \%$. Uma das causas possíveis dessa redução foi a diminuição da atividade econômica.

Outras pesquisas detalharam os impactos da pandemia no trabalho dos jornalistas e comunicadores, inclusive no Brasil. A percepção dos resultados dessas pesquisas pode nos dar um panorama mais amplo de qual foi a amplitude alcançada por essas repercussões.

\section{O trabalho do jornalista no contexto da Covid-19}

Para termos uma ideia da repercussão que a pandemia da Covid-19 está causando em instituições que lidam com a atividade jornalística, o Centro Internacional para Jornalistas (ICFJ, de sua sigla, em inglês) e a Universidade de Colúmbia lançaram uma pesquisa global para mapear esses efeitos -os dados ainda não foram sistematizados. A pesquisa considera que o jornalismo enfrenta um potencial 'evento de extinção'3, daí a urgência do estudo. A pesquisa, intitulada 'Jornalismo e o Projeto Pandêmico', busca explicar i) como a pandemia está transformando os negócios e a prática do jornalismo; ii) que ameaças à liberdade de imprensa e à segurança do jornalismo surgiram com a Covid-19 e como os jornalistas e as organizações de notícias estão respondendo a eles; iii) como jornalistas e organizações de notícias estão vivenciando e trabalhando para combater o fluxo de desinformação que acompanha a pandemia.

$\mathrm{Na}$ mesma perspectiva, a Federação Nacional de Jornalistas (Fenaj), em articulação com sindicatos de jornalistas profissionais dos estados brasileiros, coletou

\footnotetext{
3 Disponível em https://www.icfi.org/our-work/journalism-and-pandemic-survey. Acesso em $30 / 7 / 2020$
} 
dados sobre os impactos da Medida Provisória 936 (MP9364) sobre as relações de trabalho dos jornalistas nesse período de pandemia. De acordo com o levantamento ${ }^{5}$, com dados pinçados até julho, quando já havíamos atravessado o pico da primeira onda da Covid-19 na maioria dos estados, 3.930 profissionais jornalistas que trabalham em redações com carteira assinada, nas bases de 16 sindicatos do país, tiveram redução de salário e de jornada durante a pandemia. Outros 81 jornalistas tiveram seus contratos de trabalho suspensos e 205 foram demitidos.

O maior impacto foi na redução de $25 \%$ dos salários e das jornadas (3.808 jornalistas alcançados), medida que não necessita da assinatura de acordos coletivos de trabalho. A Fenaj ainda trabalha com a subnotificação dos dados, uma feita que é a empresa que notifica as entidades sindicais sobre a ocorrência de acordos individuais. No Ceará, embora sem pactuar acordo coletivo, o Sistema Verdes Mares, maior empregador, aplicou ajuda compensatória a todos os 124 afetados com a redução de $25 \%$ dos salários e carga horária, de forma a preservar quase a totalidade da renda que o funcionário tinha antes da implantação da MP.

Pesquisa realizada pelo CPCT/USP (FÍGARO, 2020), específica sobre os impactos da pandemia da Covid-19 sobre os comunicadores brasileiros, atesta a transformação nas condições e relações de trabalho. No período em que o questionário (survey) esteve aberto ao acesso dos comunicadores, via sites do CPCT e das instituições que colaboraram com o levantamento, de 5 a 30 de abril de 2020, foram alcançados 557 respondentes, com 38 oriundos do Ceará (SILVA; COSTA, 2020). Na sistematização e interpretação dos dados, a redução salarial e de horas de trabalho também aparece como uma grande preocupação. A pesquisa, no entanto, chama atenção para um grupo específico. No caso, comunicadores sem vínculo empregatício. Trabalhando "em sistema de freelancer ou pessoa jurídica, microempreendedor individual (MEI) etc., são os que têm mais incertezas sobre a situação imediata, o amanhã, que bate

\footnotetext{
${ }_{4}^{4}$ Devido à pandemia da Covid-19, o Governo Federal publicou a Medida Provisória $\mathrm{n}^{\circ}$ 936, de $1^{\circ}$ de abril de 2020, que foi convertida na Lei 14.020/2020 e que instituiu o Programa Emergencial de Manutenção do Emprego e da Renda e trata sobre medidas trabalhistas para enfrentamento do estado de calamidade pública. Entre essas medidas, a possibilidade da redução salarial, com a consequente redução de carga horária de trabalho; e própria suspensão temporária dos contratos de trabalho.

${ }^{5}$ Disponível em http://www.sindjorce.org.br/mp-936-mais-de-4-mil-jornalistas-do-paistiveram-impactos-salariais-durante-a-pandemia/. Acesso em 30 jul 2020.
} 
à porta, e não têm perspectivas de continuidade das atividades e da fonte de recursos". (FÍGARO, 2020, p. 14).

A pesquisa dá conta da situação profissional dos jornalistas, de maneira individualizada. E os impactos da pandemia são detalhados em relação aos profissionais que trabalham essencialmente 'no' ou 'para' o mainstream, empresas de comunicação e de jornalismo ligadas ao jornalismo convencional. Para além dessa percepção, que consideramos de suma importância, nos interessa lançar um olhar para as organizações, e, especificamente, para as iniciativas que praticam um jornalismo independente, na sua relação com a Covid-19.

Partimos da hipótese que existem especificidades vinculadas ao funcionamento das iniciativas de jornalismo independente. Patrício e Silva (2019) já chamam atenção para a situação de precariedade enfrentada pelos trabalhadores das iniciativas de jornalismo independente, e pela especificidade de sua atuação regional, estabelecida pelo ethos eivado por marcadores territoriais. Como a pandemia também atuou de maneira diferenciada, em seus picos de transmissão e refluxos, de acordo com os estados e regiões no Brasil, achamos necessário se conhecer, de maneira específica, o impacto da pandemia da Covid-19 nas condições de trabalho dos trabalhadores e das organizações de jornalismo independente do Ceará. Dessa compreensão, decorrem as questões de partida desse trabalho. i) Quais os impactos da pandemia instalada pela Covid-19 em relação às iniciativas de jornalismo independente do Ceará? ii) Que alterações aconteceram em suas rotinas de produção? iii) Como sua força de trabalho foi alterada? iv) De que modo a relação com o público sofreu impactos?

Para uma contextualização da atuação do jornalismo independente no Brasil, buscamos situar historicamente seus processos, dentro dos limites do breve espaço que dispomos nesse artigo. Também trabalhamos na perspectiva de identificar as principais inquietações da pesquisa em jornalismo em torno do tema. Ambos os movimentos tentam uma aproximação em relação ao conhecimento dos processos de funcionamento de suas iniciativas, base da discussão que queremos desenvolver aqui.

\section{O funcionamento das iniciativas de jornalismo independente}

Em que pese a polissemia do conceito, o termo 'jornalismo independente' consegue ser reconhecido pelas iniciativas que elaboram propostas de trabalho com objetivos para além da mídia corporativa convencional, intencionando transformações nas 
desigualdades, seja em que âmbito for, da sociedade brasileira. Esse reconhecimento não é de agora, e abarca uma diversidade de ideias vinculadas desde a liberdade de expressão, no marco específico da produção do jornalismo; passando por reivindicações de melhores condições de qualidade de vida, ancoradas na ação de movimentos sociais; e alcançando reações de contracultura, como propostas libertárias de outros modos de viver. Por isso, e no Brasil, essa orientação na produção do jornalismo incursiona pela elaboração de folhetins, direcionados ao operariado do início do século XX; passa pela contestação à ditadura militar, entre 1964 e 1985; e serve de suporte às lutas ambientais, na década de 1990.

Já no século XXI, com a inserção tecnológica mais intensiva, a partir da facilidade de acesso à internet e ascensão do smartphone como meio de produção de informação, essas iniciativas tomam outro impulso, facilitadas pela possibilidade da mobilidade e distribuição da produção do jornalismo a baixo custo. Essa ampliação da inserção tecnológica vem acompanhada por um movimento de 'profissionalização' dessas iniciativas, resultante da inserção de jornalistas graduados no ensino superior oriundos do Programa de Apoio a Planos de Reestruturação e Expansão das Universidades Federais (Reuni), política pública do governo federal lançada em 20076. O Reuni permite uma expansão democrática do acesso ao ensino superior, o que aumenta o contingente de estudantes de camadas sociais de menor renda na universidade pública, incluindo os cursos de jornalismo. É daí que vão sair os jornalistas profissionais que, insatisfeitos com a pauta da cobertura do jornalismo convencional, começam a propor iniciativas com forte pegada no território, nas periferias, nas bordas, o que mais tarde reconheceriam como um jornalismo 'das quebradas'.

O momento tem um marco, reconhecido pelas Jornadas de Junho de $2013^{7}$, em que as expressões independentes de produção do jornalismo se incorporam ao

${ }_{6}$ O Reuni foi instituído pelo Decreto n 6.096, de 24 de abril de 2007, no segundo governo Luís Inácio Lula da Silva (PT - Partido dos Trabalhadores), quando era ministro Fernando Haddad. É uma das ações que integram o Plano de Desenvolvimento da Educação (PDE). O Plano Nacional de Assistência Estudantil (PNAES), um dos componentes do Reuni, trabalha por meio da sustentação à adoção de políticas afirmativas.

7 Dá-se o nome de Jornadas de Junho a uma série de manifestações iniciadas no dia 20 de junho de 2013, em São Paulo (SP), contra o aumento das tarifas do transporte público urbano. Rapidamente os protestos incorporaram outras reivindicações, como melhoria nas condições de moradia e trabalho, e espalharam-se pelo Brasil. No esteio das mobilizações, grupos reivindicando serem de direita iniciaram protestos mais amplos, conta o governo Dilma Rousself, que viu sua popularidade despencar. Admite-se, hoje, 
movimento midiativista. O 'registro' desse novo momento pode ser representado pela elaboração do Mapa de Jornalismo Independente, pela Pública, agência de produção de jornalismo investigativo. Entre novembro de 2016 e fevereiro de 2017, uma equipe da Pública mapeou iniciativas que respondessem a quatro critérios básicos. i) Organizações que produzissem primordialmente conteúdo jornalístico; ii) organizações que nasceram na rede, identificando os nativos digitais; iii) projetos coletivos, que não se resumissem a blogs; e iv) sites não ligados a grandes grupos de mídia, políticos, organizações ou empresas. Àqueles que preenchiam esses requisitos, numa percepção inicial, foi enviado um questionário para detalhamento e confirmação das informações. Os mesmos poderiam sugerir outras iniciativas que, sob sua ótica, satisfizessem essas definições. $O$ trabalho apontou 79 iniciativas de jornalismo independente no Brasil.

Mesmo com as fragilidades metodológicas apresentadas, alguns dados explicitados pelo Mapa reafirmam o marco de 2013 no jornalismo independente no Brasil. Na interpretação da Pública ${ }^{8}$, no período entre "1996 e 2006, o surgimento de veículos de jornalismo independente no Brasil passa por períodos instáveis, com alguns anos sem registro de criação de organizações". A partir de 2006 "é possível observar o surgimento de ao menos um veículo por ano. De 2013 para 2014, a fundação de novas organizações saltou de cinco para 18".

Não é à toa que a academia percebe esses movimentos. Dois ${ }^{9}$ de seus núcleos de pesquisa passam a trabalhar diretamente com a temática 'jornalismo independente'. $\mathrm{O}$ Centro de Pesquisa em Comunicação e Trabalho (CPCT/USP) e o Práxis no Jornalismo (PráxisJor/UFC) iniciam, respectivamente em 2016 e 2017, projetos de pesquisas sobre jornalismo independente. Como referência, elegem como ponto de partida o Mapa da Pública. O CPCT trabalha na pesquisa 'As relações de comunicação e as condições de produção no trabalho de jornalistas em arranjos econômicos alternativos as corporações de mídia'. O PráxisJor, de forma bem menos estruturada e com objetivos bem mais

que as Jornadas representaram o início de sua derrocada, acontecida com o processo de golpe-impeachment em 2016.

8 Disponível em https://apublica.org/2016/11/o-que-descobrimos-com-o-mapa-dojornalismo-independente/. Acesso em 28 jul 2020.

9 Mencionamos, também, a produção que vem sendo realizada pelo Programa de Pósgraduação em Jornalismo e pelo Programa de Pós-Graduação em Sociologia Política, da Universidade Federal de Santa Catarina, que investem na categoria 'governança' como orientadora das discussões sobre jornalismo independente (GIUSTI, 2019; TAVARES, 2019; MICK, CHRISTOFOLETTI, 2018; MICK, TAVARES, 2017; LIMA, 2017) 
modestos, inicia o projeto 'A atuação de grupos independentes de produção de Jornalismo em plataformas digitais e as repercussões na identidade jornalística', no âmbito do Programa Institucional de Bolsas de Iniciação Científica (Pibic) da Universidade Federal do Ceará (UFC).

As constatações ao que o CPCT/USP chega vão desde as dificuldades no trabalho do jornalista, o que o força a procurar alternativas aos postos de trabalho do mainstream (FÍGARO; NONATO, 2017); passando pela percepção da diversidade de perfis desses arranjos e a multiplicidade de objetos de interesse (NONATO; PACCHI FILHO; FÍGARO, 2018); e chegando a questionamentos sobre o próprio sentido de independência desses arranjos (FÍGARO, 2018). O PráxisJor/UFC, a partir dos desdobramentos do projeto inicial, discute desde a própria noção de independência dessas iniciativas, a partir de análises autodeclaratórias (PATRÍCIO; BAPTISTA, 2020); descobre um ethos vinculado à regionalidade, num contexto de territorialização/desterritorialização da produção desse jornalismo independente (PATRÍCIO; SILVA, 2019); e identifica a territorialidade como fator de (in)dependência na produção de jornalismo independente, analisando especificamente iniciativas do Nordeste do Brasil (PATRíCIO, 2019).

Mas uma das principais considerações dessas pesquisas é reforçar que um dos disparadores para a estruturação dessas iniciativas está na intrínseca relação entre as orientações do sistema capitalista e o jornalismo resultante da mídia corporativa convencional, num ambiente de reestruturação produtiva, já constatada também em estudos anteriores (MEDINA, 1982; OLIVEIRA, 2005; FONSECA; SOUZA, 2006; PEREIRA, 2008; FÍGARO, 2013; DEAK; FOLETTO, 2013; GALLAS, 2014; ROXO; GROHMANN, 2014; DEUZE, 2014; CHARRON \& DE BONVILLE 2016; FÍGARO, 2018). A plataformização da produção do jornalismo (FÍGARO; SILVA, 2020; GROHMANN, 2020a, 2020b), e as condições de precarização daí resultantes, entra como elemento protagonista dessa relação. Patrício (2019) já identificara uma situação específica, relacionada aos trabalhadores que atuam em iniciativas de jornalismo independente. Ele percebe que o vínculo estabelecido passa pela colaboração eventual ou voluntariado, sem contrato de trabalho estabelecido.

Reconhecidas as dinâmicas de funcionamento das iniciativas de jornalismo independente, e suas especificidades, podemos iniciar a discussão sobre a relação que mantiveram com a pandemia da Covid-19. 


\section{Procedimentos metodológicos}

A pesquisa exploratória (GIL, 1994) que deu origem a este trabalho, parte de uma base de dados de 63 iniciativas de jornalismo independente do Ceará (COSTA; ARAÚJO; LIMA, 2020) catalogadas pelos participantes do grupo de pesquisa PráxisJor - Práxis no Jornalismo, vinculado ao Programa de Pós-graduação em Comunicação da Universidade Federal do Ceará. O procedimento de catalogação, realizado ao longo do segundo semestre de 2019 e primeiros três meses de 2020, incorpora elementos da triangulação de métodos (FIGARO, 2018; DENZIN \& LINCOLN, 2006, JANKOWSKI \& WESTER, 1993), por meio da técnica de bola de neve (BALDIN; MUNHOZ, 2011).

$\mathrm{Na}$ segunda fase, foi encaminhado um questionário online a essas iniciativas, no dia 18 de maio de 2020. Um olhar mais atento à base de dados refinou esse encaminhamento a 51 iniciativas, atentando para condições de não funcionamento mesmo antes do período da pandemia ou que não se encaixavam enquanto parâmetros mínimos de iniciativas de jornalismo. Para isso, trabalhamos com 'marcadores de jornalismo' (COSTA; ARAÚJO; LIMA, 2020). Na semana de 25 a 29 de maio de 2020, foram ainda encaminhadas mensagens, via aplicativo WhatsApp, a 32 dessas iniciativas. Das 51 iniciativas validadas, 17 (33,3\%) responderam ao questionário.

Do questionário, constavam seções com questões sobre dados gerais de identificação, incluindo o município de atuação da iniciativa; informações relacionadas à força de trabalho e as relações de trabalho estabelecidas; as funções desempenhadas pelos profissionais e colaboradores; as condições de trabalho, incluindo a infraestrutura disponibilizada pela iniciativa; a periodicidade e o nível de produção jornalística da iniciativa; as fontes de informação acessadas para a produção jornalística; considerações gerais sobre o trabalho da iniciativa, o jornalismo convencional e a atuação do jornalismo independente.

Importante salientar que, quando cabia, as informações requeridas estavam relacionadas a dois períodos distintos, correspondentes a antes e depois do início da pandemia. $\mathrm{O}$ intuito se coadunava com o objetivo do levantamento, que era exatamente perceber os impactos da Covid-19 sobre as rotinas e produção jornalística das iniciativas envolvidas. Como algumas questões eram abertas, houve a necessidade de ajustar algumas informações. Por exemplo, sobre o município de localização da iniciativa -alguns respondentes indicavam a região, como o Cariri (CE), e não o município específico. 


\section{Dados contextuais a partir do levantamento}

Uma das preocupações desse estudo, e que está na base de sua justificativa, se refere à necessidade de se estabelecer a relação entre os reflexos da pandemia da Covid19 e as iniciativas locais de jornalismo independente, destacando-se a dimensão regional em sua atuação, o que ressalta suas especificidades. Daí uma intencionalidade de não se restringir a iniciativas que atuam unicamente na Região Metropolitana de Fortaleza, capital do estado -presumindo-se que possam haver diferenciações intrarregionais.

Das 17 iniciativas respondentes, 58,8\% (10) ainda se concentram na Região Metropolitana de Fortaleza; mas sete dessas iniciativas $(41,1 \%)$, atuam na Região Metropolitana do Cariri (região Sul do estado), incluindo três no município de Juazeiro do Norte, uma no Crato e uma no município de Barbalha. Uma das iniciativas, embora tenha especificado sua atuação no Cariri, não indicou o município em que está sediada. Havia uma preocupação, também, de se alcançar, pelo levantamento, as iniciativas da região Norte do estado, cujo município polo é Sobral. No entanto, mesmo com os contatos mantidos com cinco organizações, nenhuma respondeu ao questionário.

Não houve a preocupação de se trabalhar especificamente com os profissionais jornalistas, uma feita que o estudo também se orientou por rastrear as condições de funcionamento das próprias iniciativas durante a pandemia, enquanto organizações, e não só das condições de trabalho dos profissionais. No entanto, um dado específico pode ser destacado. Dos respondentes dos 17 questionários, onze deles $(64,7 \%)$ são profissionais jornalistas, o que evidencia uma característica apontada por Rovida (2020), qual seja a tentativa de produção de um jornalismo 'profissional' a partir de sujeitos periféricos, e fato já referido nesse texto. A se levar em consideração, como condicionante, que essa situação não dá conta de uma pretensa profissionalização que alcance todos os participantes das iniciativas (e que não foi objeto do levantamento), sabendo-se que, possivelmente, a função dos respondentes dos questionários coincidia com o responsável pela gestão das iniciativas.

Outro dado contextual do levantamento, que reforça a percepção anterior, é sobre a faixa etária dos respondentes do questionário. Dos 17 respondentes, doze $(70,5 \%)$ se situavam entre 37 e 59 anos. Ao se sobrepor as duas últimas referências, uma especulação possível é que são prováveis as teses que afirmam a desilusão experimentada com a mídia corporativa convencional pelos jornalistas ou mesmo o enxugamento das redações a partir dos processos de reestruturação produtiva, o que 
tange os profissionais a buscar novas colocações fora do mainstream. Além disso, outra constatação possível é que as iniciativas de jornalismo independente estão seduzindo mais que jovens profissionais de jornalismo, os saídos dos bancos das faculdades e que estão à procura de colocação no mercado de trabalho para além da mídia corporativa convencional.

\section{Primeiras interpretações}

Algumas informações colhidas pela pesquisa sugerem a necessidade de um olhar mais específico sobre os reflexos da pandemia da Covid-19 na produção do jornalismo independente. Uma das grandes transformações impostas ao jornalismo maistream, como a toda atividade econômica, foi o trabalho home office, pela restrição dos processos de mobilidade. Isso na condição dos jornalistas serem considerados trabalhadores de serviços essenciais. Na redação do O Povo, jornal de Fortaleza, por exemplo, grande parte dos jornalistas da redação, segundo relatos pessoais colhidos pelo autor desse texto, passaram a trabalhar em casa, fato que indica que a restrição não estava condicionada aos grupos de risco. Pela pesquisa nacional realizada pelo CPCT, para $80 \%$ dos respondentes (449), o home office é a realidade do trabalho durante a pandemia (FÍGARO, 2020). Essa orientação ainda se fortalece nos dados específicos do Ceará (dados consolidados do estado), em que esse percentual amplia-se a 93\% (COSTA; SILVA, 2020).

Uma situação bem distinta se verifica entre os participantes que assumem funções de produção de jornalismo nas iniciativas de jornalismo independente -aqui incorporamos 71 participantes, referidos pelos 17 respondentes do questionário, que atuavam nas iniciativas ANTES do período da pandemia -a pergunta do questionário se referia à força de trabalho da iniciativa, dividida por funções exercidas, como editores e repórteres. Desses 71 participantes, 17 (23,9\%) NÃO trabalhavam em home Office ANTES da pandemia. Para os participantes (comunicadores, jornalistas ou não) que produzem o conteúdo jornalístico veiculado pelas iniciativas de jornalismo independente, o home office não seria uma novidade. Frente à precariedade dos recursos financeiros, e, por conseguinte, infraestruturais, esses participantes já desenvolviam seu trabalho em suas próprias casas, que muitas vezes são as sedes das iniciativas. Por conta disso, o receio de perda do trabalho ou de redução salarial convive, ao mesmo tempo, e num espectro 
mais amplo, à continuidade ou não do funcionamento da própria iniciativa, e não só de seus postos de trabalho.

Permanecendo no âmbito dos dados relativos às condições de trabalho, a pesquisa nacional informa que são os comunicadores que suprem sua 'caixa de ferramentas' durante a pandemia. "Rara foi a empresa que forneceu equipamentos para o trabalho em home office nesse período" (FÍGARO, 2020, p. 53). Foram 331 respondentes $(59,4 \%)$ que afirmaram utilizarem somente meios próprios para a realização do trabalho em casa. Na pesquisa consolidada com dados específicos do Ceará, a situação é mais aguda ainda. A "grande maioria dos respondentes $(81,6 \%)$ declara ser proprietário dos meios de trabalho utilizados durante a pandemia" (COSTA; SILVA, 2020, p. 40).

No caso das iniciativas de jornalismo independente do Ceará, alcançadas por nosso levantamento, $25 \%$ delas 'emprestaram' seus equipamentos para os trabalhadores de produção do jornalismo atuando em home office. Antes desse dado significar um seguimento da tendência da pesquisa nacional e estadual, cabe salientar que uma possibilidade, a ser averiguada com o aprofundamento do levantamento, é que não ocorreu um maior empréstimo pelo simples fato de que essas iniciativas não dispunham de equipamentos próprios para ceder aos trabalhadores, evidenciando, mais uma vez, a situação estrutural, e não conjuntural, da deficiência em torno de sua infraestrutura própria de funcionamento, como se constata a partir de seu próprio local de funcionamento, a casa do responsável pela gestão da iniciativa fazendo-se de sede da mesma.

Ainda sobre as condições de trabalho, a pesquisa nacional indagou aos comunicadores sobre o ritmo de trabalho no contexto de isolamento social devido à pandemia. Para 70\% dos respondentes (FÍGARO, 2020), o ritmo está um pouco mais pesado ou muito mais pesado que o anterior ao período da Covid-19. Na consolidação dos dados estaduais da pesquisa, no Ceará, para 18 respondentes $(47,4 \%)$, o ritmo está um pouco mais pesado, enquanto que para $14(36,8 \%)$ o ritmo é muito mais pesado (COSTA; SILVA, 2020), o que, para haver uma equiparação com a interpretação dos dados nacionais, totaliza $84,2 \%$ dos comunicadores nas duas categorias.

Quando se interroga aos respondentes das iniciativas de jornalismo independente do Ceará sobre o ritmo de trabalho, no período de pandemia, 52,9\% responderam que se situava entre muito mais tranquilo e mais tranquilo, o que abre uma distância em relação aos dados consolidados nacionalmente e no Ceará das pesquisas com os comunicadores. Duas interpretações possíveis pra esse distanciamento. A primeira, que 
as iniciativas de jornalismo independente podem não seguir os ditames da intensificação do trabalho (ANTUNES, 2018), pelo menos não no ritmo induzido pelas empresas jornalísticas em processo avançado de convergência e integração das redações, ditadas pela dinâmica imposta pela reestruturação produtiva do capitalismo; segunda, que consideramos menos provável, que os respondentes do questionário, por serem os gestores dessas iniciativas, de forma deliberada 'mascararam' os dados numa tentativa de não expor as condições de trabalho extenuantes também praticadas.

Mas por que a segunda interpretação seria menos provável? A partir de outro questionamento, constante do questionário enviado às iniciativas, indagou-se sobre o ritmo do conjunto da produção de conteúdo jornalístico mantido pela iniciativa antes e depois do período de pandemia. Se, antes da Covid-19, 35,3\% das iniciativas produziam mais de dez matérias por dia, esse volume de produção reduz-se pela metade, mantendose em apenas $17,6 \%$ no total das iniciativas durante o período de enfrentamento da pandemia. Quando verificada a produção entre 6 a 10 matérias por dia, antes da pandemia 5,9\% das iniciativas seguiam esse ritmo. Depois do início da Covid-19, são $11,8 \%$ delas que entram nessa faixa de produção, indicando que houve uma migração de produção da faixa mais alta para a imediatamente inferior.

Outra informação que o estudo buscou obter tem relação com as fontes de informação utilizadas pelas iniciativas antes e depois do início da pandemia da Covid-19. Esse é um questionamento que não está no instrumental da pesquisa nacional realizada pelo CPCT. A nós nos parece importante na medida em que pode apontar dificuldades nas rotinas de produção do conteúdo jornalístico, como, por exemplo, a partir da identificação da redução do número de matérias produzidas, já comentada aqui. Também poderia apontar a capacidade da iniciativa, mesmo com a mobilidade restringida, em continuar seu trabalho.

Em relação à variação da utilização de fontes procuradas pelas iniciativas, não ocorreu um movimento mais brusco entre os dois períodos, antes e depois do início da pandemia. Um leve acréscimo na categoria 'especialistas', eleita como fonte principal por $64,7 \%$ (antes da pandemia) e 76,5\% (depois do início da pandemia) das iniciativas, movimento que pode ser interpretado a partir da especificidade da temática em pauta, no caso a Covid-19. Causa curiosidade a redução da indicação de fontes ligadas a universidades como fontes principais para a produção do material jornalístico, uma feita que a pesquisa, principalmente na área médica, passou a dominar a cobertura do 
jornalismo mainstream. O percentual de fontes ligadas a universidades passou de $41,2 \%$ para $35,3 \%$. Uma das possibilidades aventadas para essa redução deve-se ao fato das universidades terem sustado suas atividades presenciais depois do início da pandemia, nas duas regiões metropolitanas onde as iniciativas atuam. Em se tratando de iniciativas que têm a territorialidade como base da produção de seus conteúdos jornalísticos (PATRíCIO; SILVA, 2019), essa redução poderia ser justificável.

Em outro questionamento, ainda vinculado às fontes de informação utilizadas pelas iniciativas, indagamos que fontes mais procuraram contato com as iniciativas antes e depois do início da pandemia. Nesse caso, houve uma variação considerável, na mesma categoria de fontes nomeadas 'especialistas'. Antes da pandemia, para $35,3 \%$ das iniciativas os especialistas eram as fontes que mais lhes procuravam. Depois do início da pandemia, esse percentual salta para 70,6\%. A procura pelas iniciativas por essas fontes pode ser atribuída à facilidade de acesso, pela prática de um jornalismo de base territorial local. Ao mesmo tempo, sinaliza para uma percepção de credibilidade vinculada à produção jornalística dessas iniciativas. Essa interpretação pode ser referenciada pelas respostas dadas a outro questionamento, sobre o nível de dificuldade de acesso às fontes de informação depois do início da Covid-19. Sobre isso, para 70,6\% das iniciativas, o acesso a essas fontes não melhorou nem piorou ou até melhorou.

\section{Outras considerações}

A primeira observação a ser feita é que a propensão a estabelecer um processo de trocas de ideias e de percepções, a partir desse estudo, e com as iniciativas de jornalismo independente que dele participaram, foi prejudicada pela própria continuidade da pandemia da Covid-19, que força ao distanciamento físico social. Desse modo, a ideia de, num segundo momento, acompanhar, observar, conhecer, interagir com os ambientes de trabalho dessas iniciativas teve de ser adiada. Salientar também que esse estudo faz parte de uma pesquisa mais ampla, ainda em desenvolvimento, e com previsão de finalizar no primeiro semestre de 2021, que aprofunda outras dimensões da ação das iniciativas de jornalismo independente do Ceará.

Em torno dessa pesquisa mais ampla, já avançamos em direção a uma proposta de nucleação dessas iniciativas, levando-se em consideração critérios como marcadores jornalísticos de suas produções, ethos discursivo vinculado a uma determinada territorialidade e à própria regionalidade relacionada à sua atuação. A compreensão do 
que venha a se constituir essa 'regionalidade', em tempos de plataformas digitais de distribuição da informação, é algo a ser averiguado com mais detalhes. Patrício (2019) já alertava para uma possível contradição, entre acesso, a princípio, universal à produção da informação e vínculo territorial delimitado, com repercussões nas possibilidades de sustentabilidade financeira dessas iniciativas. Ainda sobre isso, o reconhecimento dessa produção pelo público que é fonte e ao mesmo tempo destinatário dessa produção, delimitado fisicamente pelo território de atuação, é uma discussão a ser aprofundada.

Até agora, a discussão sobre o conceito de 'jornalismo independente' foi, de certa maneira, 'evitado', frente sua polissemia. A saída foi trabalhar com a análise de autodeclarações institucionalizadas dessas iniciativas, principalmente em seus sites, incluindo as redes sociais digitais. Talvez essa discussão não possa mais esperar. E tomar a polissemia, que constitui o conceito, em sua positividade, uma ingerência da diversidade de modelos e propostas de jornalismo que não se confundem, em seus princípios, rotinas de produção e interesses com aquele praticado pela mídia corporativa convencional. A ver!

\section{Referências}

ANTUNES, Ricardo. O privilégio da servidão. O novo proletariado de serviços na era digital. São Paulo: Boitempo, 2018.

BALDIN, N., MUNHOZ, Elzira. Snowball (bola de neve): uma técnica metodológica para pesquisa em educação ambiental comunitária. EDUCERE, 2011 Disponível em: http://educere.bruc.com.br/CD2011/pdf/4398 2342.pdf.

CHARRON, Jean. DE BONVILLE, Jean. Natureza e transformação do jornalismo. Florianópolis: Insular; Brasília: FAC Livros, 2016.

COSTA, Rafael R.; ARAÚJO, Mayara C. B.; LIMA, Raphaelle C. B. Apontamentos para um perfil dos arranjos alternativos de jornalismo no Ceará. Cambiassu, v. 15, n. 25, 2020.

DEAK, Andre; FOLETTO, Leonardo. Processos emergentes do jornalismo na internet brasileira: "novos jornalistas" na era da informação digital. Rev. Estud. Comun., Curitiba, v. 14, n. 33, p. 13-28 jan, 2013.

DENZIN, Normam K., LINCOLN, Yvonna S. O planejamento da pesquisa qualitativa. Porto Alegre: Penso, 2006.

DEUZE, Mark. O jornalismo, a vida na mídia e a sociedade empreendedora. Revista Parágrafo, v. 2, n. 2, 2014.. 
FENAJ. Aplicação da MP 936 e outras questões relacionadas à Pandemia de Covid-19. Federação Nacional dos Jornalistas (Fenaj), 2020. Dados não sistematizados, repassados ao autor.

FÍGARO, Roseli (Coord.). Relatório dos resultados da pesquisa [recurso eletrônico]: como trabalham os comunicadores em tempos de pandemia da Covid-19? / São Paulo: ECA-USP, 2020. Disponível em http://www2.eca.usp.br/comunicacaoetrabalho/wpcontent/uploads/Relat\%C3\%B3rio Executivo Covid19- CPCT2020-2.pdf.

. Jornalismos e trabalho de jornalistas: desafios para as novas gerações no século XXI. Revista Parágrafo. FIAM-FAAM. V. 2, n.2., 2014.

2013.

. (Org.). As mudanças no mundo do trabalho do jornalista. São Paulo: Atlas,

FÍGARO, Roseli; SILVA, A. F. M. A comunicação como trabalho no capitalismo de plataforma: o caso das mudanças no jornalismo. Revista Contracampo, v. 39, p. 1-15, 2020.

FÍGARO, Roseli; NONATO, Cláudia. Novos 'arranjos econômicos' alternativos para a produção jornalística. Contemporânea | comunicação e cultura - v.15 - n.012017.

FONSECA, V. P. S; SOUZA, P. H. R. O pós-fordismo na produção jornalística. Intexto, Porto Alegre: UFRGS, v. 2, n. 15, p. 1-18, julho/dezembro, 2006.

GALLAS, Débora. A contribuição do jornalismo para o saber social. Caminhos para uma prática responsável e para o fomento da cidadania. Chasqui, n. 127, 2014.

GIL, Antonio Carlos. Métodos e técnicas de pesquisa social. 6.ed. São Paulo: Atlas, 2008.

GIUSTI. Tânia Regina de Faveri. A governança nos novos arranjos de jornalismo: um estudo do The Intercept Brasil. Dissertação (mestrado) - Universidade Federal de Santa Catarina, Centro de Comunicação e Expressão, Programa de Pós-graduação em Jornalismo, Florianópolis, 2019.

GROHMANN, R. N. A Comunicação na Circulação do Capital em Contexto de Plataformização. LIINC EM REVISTA, v. 16, p. 1-15, 2020 a.

Plataformização do trabalho: entre dataficação, financeirização e racionalidade neoliberal. Eptic On-Line, v. 22, p. 106-122, $2020 \mathrm{~b}$.

O trabalho do jornalista a partir dos processos comunicacionais e produtivos: dimensões teóricas em cenário de flexibilização e tensionamentos identitários. Estudos em Jornalismo e Mídia, v. 13, n.1, 2016.

JANKOWSKI, N. W., WESTER, F. La tradición cualitativa en la investigación sobre las ciencias sociales: contribuciones a la comunicación de masa. In: JENSEN, K.B.; JANKOWSKI, N. M.(Eds.) Metodologias cualitativas de investigación en 
comunicación de masas. Barcelona: Bosch, 1993.

LIMA, S. P. Governança Social, Produção e Sustentabilidade para um jornalismo de novo tipo [S.I.:s.n.:s.d.]. GPSJOR. Disponível em: http://ppgjor.posgrad.ufsc.br/files/2012/01/2017-01-30-GPS-JORVERSÃO-FINALPosjorUFSC-SAMUEL-LIMA.pdf. Acesso em 13/7/2020.

MEDINA, Cremilda de Araújo. Profissão jornalista: responsabilidade social. Rio de Janeiro: Forense-Universitária, 1982.

MICK, J.; CHRISTOFOLETTI, R. Inovações na governança jornalística diante da crise. In: COLUSSI, Juliana Gomes-Franco; SILVA, Flávia; ROCHA, Paula MELANI. Periodismo ubícuo: convergência e innovación en las nuevas redacciones. Bogotá: Lobo Editions, 2018.

MICK, J.; TAVARES, L. A governança do jornalismo e alternativas para a crise. Brazilian Journalism Research: journalism theory, research and criticism. [S.I.], v. 13, n. 2, 2017, p. 120-145. Disponível em: https://bjr.sbpjor.org.br/bjr/download/948/924. Acesso em $13 / 7 / 2020$.

NONATO, Cláudia; PACHI FILHO, Fernando Felício; FÍGARO, Roseli. Relações de comunicação em novos arranjos alternativos e modelos de produção de notícia. Líbero. $\mathrm{n}$. 41, 2018.

OLIVEIRA, Michele Roxo. Profissão jornalista: um estudo sobre representações sociais, identidade profissional e as condições de produção da notícia. Dissertação (Mestrado em Comunicação) - Programa de Pós-graduação em Comunicação - Unesp, Bauru, 2005.

PATRÍCIO, Edgard; BAPTISTA, Raphaelle. Elementos de identidade em iniciativas de jornalismo independente. Extraprensa, São Paulo, v. 13, n. 2, p. 217 - 231, 2020.

PATRÍCIO, Edgard; SILVA, Naiana R. Territorialidade e ethos em iniciativas de jornalismo independente do Nordeste do Brasil. Revista Brasileira de Gestão e Desenvolvimento Regional, v. 15, p. 183-195, 2019.

PATRÍCIO, Edgard. Territorialidade como fator de (in)dependência em iniciativas de jornalismo em plataformas digitais no Nordeste do Brasil. 170 Encontro Nacional de Pesquisadores em Jornalismo. UFG - Goiânia (GO) - Novembro de 2019. Disponível em http://sbpjor.org.br/congresso/index.php/sbpjor/sbpjor2019/paper/viewFile/1947/1255.

PEREIRA, F. H. Os jornalistas intelectuais no Brasil: identidade, práticas e transformações no mundo social. Tese (Doutorado em Comunicação) - Programa de Pósgraduação em Comunicação da Universidade de Brasília, 2008.

ROVIDA, Mara. Jornalismo das periferias: o diálogo solidário nas bordas urbanas. Curitiba: CRV, 2020.

ROXO, Michelle; GROHMANN, Rafael. Sentidos do Empreendedorismo no Campo Profissional Jornalístico. Comunicom 2014. Disponível em 


\section{四 \\ PautaGeral}

http://www.espm.br/download/Anais Comunicon 2014/gts/gtum/GT01 Grohmann.pdf. Acesso em 11/07/2017.

SILVA, Naiana R.; COSTA, Rafael R. Relatório dos resultados da pesquisa [recurso eletrônico]: como trabalham os comunicadores em tempos de pandemia da Covid-19? Dados do Ceará. 2020. Disponível em https://80ca21c8-470f-4e0b-9cc7f21bd9d9a93a.usrfiles.com/ugd/80ca21 55e090bc624741219322a567cb2dd2d9.pdf.

TAVARES, Luisa. O jornalismo das periferias de São Paulo entre a experimentação e a atualização de práticas convencionais. Dissertação (mestrado) - Universidade Federal de Santa Catarina, Centro de Filosofia e Ciências Humanas, Programa de Pósgraduação em Sociologia Política, Florianópolis, 2019.

Envio: 25 out 2020

Aceite: 09 dez 2020 